\title{
Postgraduate experiential learning is essential for surgical maturation
}

\author{
Richard J. Shemin, MD
}

\author{
From the Division of Cardiothoracic Surgery, Ronald Reagan UCLA Medical, Center Los Angeles, Calif; and the \\ David Geffen School of Medicine at UCLA, Los Angeles, Calif. \\ Disclosures: Author has nothing to disclose with regard to commercial support. \\ Received for publication Aug 12, 2015; accepted for publication Aug 12, 2015; available ahead of print Sept 19 , \\ 2015. \\ Address for reprints: Richard J. Shemin, MD, 100 UCLA Medical Plaza, Suite 730, Los Angeles, CA 90095 \\ (E-mail: Rshemin@mednet.ucla.edu). \\ J Thorac Cardiovasc Surg 2015;150:1069-70 \\ $0022-5223 / \$ 36.00$ \\ Copyright (c) 2015 by The American Association for Thoracic Surgery \\ http://dx.doi.org/10.1016/j.jtcvs.2015.08.044
}

As chair of the American Board of Thoracic Surgery, I am fully aware of the requirements candidates must meet to take the Certification and Qualifying examinations administered by the Board. Eligibility for the examinations requires the resident to have met index case requirements and attestation by the program director and faculty that the resident is competent to enter independent clinical practice. But what does that statement really mean?

Cognitive knowledge, surgical technical expertise, and clinical judgment are all part of the maturation process of each surgeon. The teachings of surgical technique, judgment, and anticipation of the variability of each procedure take years to master. In addition, complex procedures that are rarely performed or procedures that are combinations of simpler operations (such as valve replacement or repair, aortic aneurysm replacement, and coronary revascularization) requires great skill, careful planning, and the ability to transition smoothly from one part of the procedure to another to perform the necessary maneuvers efficiently, expertly, and in a timely manner. Cardiopulmonary bypass time and crossclamp time can in part be measures of surgical proficiency.

The surgeons completing our training programs have limited if not reduced experiential learning imposed by work hour limitations. Index case lists are met, but the high degree of attending oversight imposed by the medical legal environment and the complexity of surgical pathology affects the autonomy that trainees have before going into surgical practice. It is therefore not surprising that the years of surgical practice after residency training provide valuable experience, knowledge, judgment, and technical skills required to become a master cardiac surgeon.

The article in this issue of the Journal by Burt and colleagues, ${ }^{1}$ represents an attempt to measure this relationship. Burt and colleagues performed a learning curve analysis with crossclamp and cardiopulmonary bypass times used

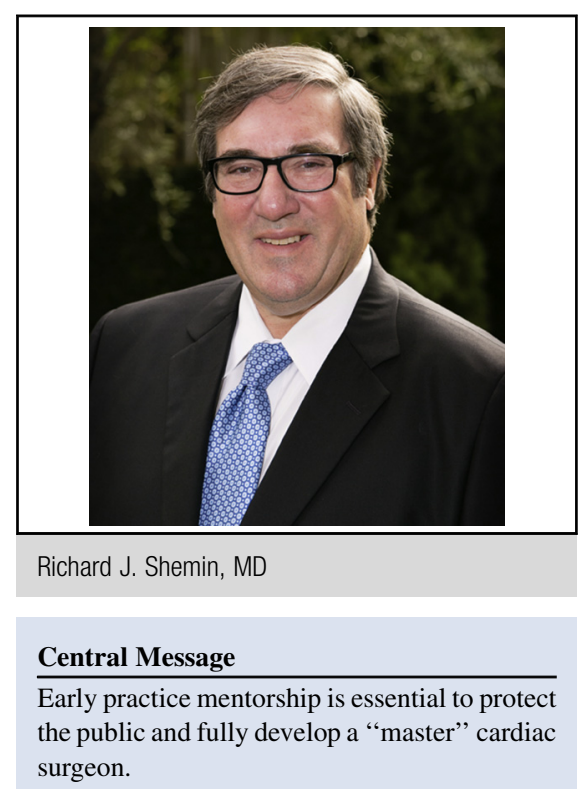

See Article page 1061 .

as measures of proficiency. Outcomes by surgeon were measured by 30-day mortality as well as long-term survival. This study was performed at a single academic institution with 10 surgeons for a variety of common procedures. They found that increased surgeon experience, measured as years in practice, was associated with improved efficiency and late survival in aortic valve replacement, mitral valve repair, and mitral valve replacement combined with aortic valve replacement. A trend toward improved survival for their patients with mitral valve replacement was also found, but there was not a relationship for coronary artery bypass grafting. The predictive effect of surgical experience on 30-day mortality was only found for mitral valve repair, mitral valve replacement, and mitral valve replacement combined with aortic valve replacement. Another measure for experience in addition to years in practice is accumulative case volume for each procedure. Cumulative case volume was found to be a significant predictor of long-term survival in aortic valve replacement combined with mitral valve repair only. Understanding the reason for the impact on late outcomes requires further study. It is easier to understand the impact on 30-day outcomes.

These findings challenge the traditional view that case volume is the primary driver, not necessarily years in 
practice. Indeed, the most experienced surgeons in the data set have well-defined valve practices and are known for their minimally invasive surgical approaches, high volumes, and excellent durability of their mitral valve repairs. These factors may bias their data.

Personally, I believe that years in practice enhances surgical experience and judgment. Case volume, however, is also important if one is to master a procedure. Perhaps the combination of years and cumulative case volume is the most important metric. The case volume must be procedure specific; consider complex aortic root \& arch procedures.

The practical implication of this study, measuring the continued learning curve of surgeons as years in practice and case experience accumulate, is to acknowledge that the attestation by residency program directors and faculty that a newly certified surgeon is "prepared for independent practice" is a highly qualified statement. It should be clearly acknowledged that the scope of practice of the new surgeon should be monitored and perhaps limited until time in practice and case experience have accumulated, allowing mastery of those complex and less commonly performed procedures. Consider the new trainee on call and facing a complex type A aortic dissection alone!

Our goal as a cardiac surgery community is to ensure patient safety and provide each patient with a surgeon who has the skills and experience to ensure optimal outcomes and minimizing morbidity. All surgical groups, whether academic or private practice, need to be organized to provide the junior surgeons continued mentorship, technical help, and oversight. Their learning curve will be accelerated, and patient safety as well as clinical outcomes will be optimized. We all carry the responsibility to be able to assure the public that our cardiac surgical workforce places the focus on excellence for each patient we encounter and that we are organized to provide all patients with surgeons who have the appropriate skills to treat their specific illnesses.

\section{Reference}

1. Burt BM, ElBardissi AW, Huckman RS, Cohn LH, Cevasco MW, Rawn JD, et al. Influence of experience and the surgical learning curve on long-term patient outcomes in cardiac surgery. J Thorac Cardiovasc Surg. 2015;150:1061-8.e3. 